\title{
The potential impact of the COVID-19 pandemic on antimicrobial resistance and antibiotic stewardship
}

\author{
Supram Hosuru Subramanya ${ }^{1}$ (D) Daniel M. Czyż $^{2}$ (D) Krishna Prasad Acharya ${ }^{3}$. \\ Hilary Humphreys ${ }^{4,5}$
}

Received: 2 January 2021 / Accepted: 4 May 2021/Published online: 25 May 2021

(C) Indian Virological Society 2021

\begin{abstract}
The rapid emergence and spread of antimicrobial resistance continue to kill an estimated 700,000 people annually, and this number is projected to increase ten-fold by 2050 . With the lack of data, it is uncertain how the COVID-19 pandemic will affect antimicrobial resistance. Severe disruption of research, innovation, global health programs, and compromised antimicrobial stewardship, infection prevention and control programs, especially in low-and middle-income countries, could affect antimicrobial resistance. However, factors such as strict lockdown, social distancing, vaccination, and the extensive implementation of hand hygiene and face masks, with limited international travel and migration, may also contribute to decreasing AMR. Although the impact of COVID-19 on AMR is global, the adverse effect is likely to be worse in
\end{abstract}

Supram Hosuru Subramanya

supram.gowda@gmail.com

Daniel M. Czyż

dczyz@ufl.edu

Krishna Prasad Acharya

kriaasedu@gmail.com

Hilary Humphreys

hhumphreys@rcsi.ie

1 Department of Medical Microbiology, Manipal College of Medical Sciences, Pokhara, Nepal

2 Department of Microbiology and Cell Science, University of Florida, Gainesville, FL, USA

3 Animal Quarantine Office, Budhanilkantha, Kathmandu, Nepal

4 Department of Clinical Microbiology, RCSI, Dublin, Ireland

5 Department of Microbiology, Beaumont Hospital, Dublin, Ireland
LMICs. In this article, we explore the possible impact of the current pandemic on antibiotic resistance.

Keywords LMIC · COVID-19 · Coronavirus · Antibiotics - Antimicrobial resistance

\section{Introduction}

The current coronavirus disease 2019 (COVID-19) pandemic has reached every country, causing massive disruption in the global economy and, most importantly, resulting in the loss of many human lives [59]. As of March 2021, COVID-19 affected over 128 million people and claimed nearly three million lives worldwide [62]. While the development of effective therapies and vaccines is ongoing, different variants of the virus emerge and pose a new and continuous risk [20]. As such, the management of COVID-19 often includes the use of prophylactic broadspectrum antimicrobials [42]. Since the beginning of the pandemic, much of the emphasis has been placed on COVID-19 diagnosis and disease management, and the impact on antimicrobial resistance (AMR) has been largely overlooked. Strict implementation of antimicrobial stewardship (AS) and infection prevention and control (IPC) measures are imperative to prevent the development and spread of AMR. Therefore, disruption in AS measures driven by the ongoing pandemic may fuel the expansion of AMR globally. There are currently no sufficient data to forecast the consequences of COVID-19 on the development and spread of antibiotic-resistant bacteria. As such, it is unclear how the pandemic will impact AMR. Recent reports suggest a massive disruption in health services worldwide could exacerbate AMR, but the actual impact remains elusive [4]. Here, we discuss and highlight 
potential pandemic-related factors that may have a longterm effect on AMR, mainly focusing on low-and middleincome countries (LMICs).

\section{Nosocomial infections, prophylaxis, and self- medication}

COVID-19 is a disease caused by Severe Acute Respiratory Syndrome Coronavirus-2 (SARS-CoV-2); as such, antibacterials (antibiotics) will not directly affect the virus. Superimposed bacterial pneumonia has been observed in a histopathological study of lung tissue samples taken from post-mortem COVID-19 patients, indicating the manifestation of secondary infections [51]. Coronaviruses, including SARS-CoV-2, attenuate interferon-gamma (IFN$\gamma)$ [54]. This reduced IFN response is closely associated with compromised immunity, which predisposes individuals to opportunistic nosocomial bacterial infections [38]. Common etiological agents of nosocomial pneumonia, like Klebsiella pneumoniae, limit the NF-кB-mediated immune response, leading to immunosuppression [6], which further increases the severity of SARS-CoV-2 infection.

Mechanical ventilation is associated with $86 \%$ of all hospital-acquired pneumonia, which requires antibiotic intervention [39]. Such a high association between mechanical ventilation and pneumonia is concerning, given that the data collected from 920 different hospitals in Germany show that $17 \%$ of hospitalized COVID-19 patients received this supportive care [31]. COVID-19 patients may require intensive care unit (ICU) admission for ventilation and the likely administration of antibiotics. Additionally, antibiotics are commonly used as prophylaxis to prevent bacterial respiratory diseases among patients afflicted by viral infections [33]. Likewise, antibiotic prophylaxis is also part of COVID-19 management [42]. Such conscious use of antibiotics as prophylaxis against opportunistic or nosocomial bacterial infections is often thought to be necessary, as secondary bacterial infections are mainly responsible for high mortality in patients suffering from viral infections $[34,38]$. Therefore, physicians may feel obliged to prevent possible bacterial and fungal super-infections by providing antimicrobial prophylaxis and supportive therapies.

At the early stage of the pandemic, there were reports of the highest (50-95\%) prevalence of COVID-19-associated secondary bacterial and fungal infection, mainly reported in China [66, 68]. However, subsequent reports from other parts of the world indicate that only a small proportion of COVID-19 patients had a secondary infection and required critical care and antimicrobial use [42]. Recent data from Singapore, Thailand, Spain, China, and the US, suggest that the overall prevalence of bacterial infection in COVID-19 patients was $6.9 \%$, with a higher occurrence among critically ill patients [32]. Another comprehensive meta-analysis of COVID-19 co-infection studies revealed a high antibiotic prescription rate of $72 \%$ among COVID-19 patients, yet, only $8 \%$ had bacterial/fungal co-infection [42]. Despite a relatively low ICU admission rate among COVID-19 patients in China (1 out of 62 ), Xu et al. reported that $45 \%$ were still treated with antibiotics [63]. In contrast, in the UK, $74.5 \%$ of patients received such treatment [21]. The International Severe Acute Respiratory and Emerging Infection Consortium (ISARIC) reports that out of 20,114 COVID-19 patients, $83.6 \%$ received antibiotics. Among ICU patients, that number was as high as $91.4 \%$, despite only a small proportion having confirmed bacterial infection [29, 42]. Additionally, broad-spectrum antibiotics are usually used with COVID-19 patients, and nearly two-thirds of prescribing physicians admit to a lack of guidelines [7, 42]. A similar use of antibiotics has also been observed across other SARS-CoV-2 affected countries, although, in most cases, the prevalence of secondary infections was very low [5, 18, 28, 32, 44, 53]. Collectively, COVID-19-related overuse of antimicrobials and steroids is evident and will likely continue until the end of the pandemic.

The National Institutes of Health COVID-19 Treatment Guidelines Panel recommends empiric antibiotic prophylaxis for moderate illness in patients with suspected bacterial pneumonia or sepsis, and if there is no evidence of bacterial infection during daily monitoring, antibiotics should be reduced or stopped [39]. The WHO also does not recommend antibiotic prophylaxis for moderate COVID-19 illness unless a bacterial infection is suspected [26]. However, such recommendations are more likely to be adhered to in high-income countries (HICs) with well-developed healthcare, access to rapid diagnostics and clinical laboratories.

The broad availability of over-the-counter antibiotics in LIMCs, low COVID-19 testing capacity, poverty, and inaccessibility to healthcare, could contribute to self-medication in undiagnosed but symptomatic individuals. In fact, an increase in self-medication with over-the-counter drugs has been associated with the ongoing pandemic $[37,52]$. Self-medication with antibiotics is more common in developing countries [23], and COVID-19 is likely to exacerbate such practice, which will inevitably contribute to AMR [1, 45, 65]. Collectively, an increase in nosocomial infections, antibiotic prophylaxis, and self-medication driven by the pandemic will likely contribute to AMR.

\section{Remote prescribing}

Face-to-face primary and secondary care is increasingly being replaced by telemedicine and teledentistry in both HICs and LMICs [11, 35]. Martinez et al. report that over 
$66 \%$ of patients who used telephone consultations for respiratory tract infections were prescribed antibiotics [36]. Such a high antibiotic prescription rate was associated with increased patient satisfaction. These numbers are much higher than in-person visits for acute respiratory infections, which have a $14.7 \%$ antibiotic prescription rate (67,974,312 prescriptions over 461,647,174 visits) [48]. Data from The National Health Service (NHS) in England (April 1 to August 31, 2020) revealed that despite a 50\% decrease in face-to-face appointments during the first five months of the lockdown, the antibiotic prescriptions increased by over $6 \%$, which perhaps could be explained by the described misuse of antibiotics in telemedicine [3]. In another study conducted in England, a HIC, an increase in prescriptions of a broad-spectrum $\beta$-lactam/ $\beta$-lactamase inhibitor combination was detected among the older population; however, the overall antibiotic prescribing volume decreased [67]. Such inappropriate use of antibiotics and its consequence on AMR are likely higher in LMICs that lack proper AS guidance and support programs, especially those related to remote prescribing; though, the exact effect of remote consultation on antibiotic prescription is still not conclusive [27]. Dentistry has also significantly contributed to the increase in antibiotic prescriptions. Reports from England reveal that COVID-19-related restricted access to dentistry increased antibiotic prescriptions by $25 \%$ [47]. Overall, global lockdowns increased the volume of remote medical and dental appointments across LMICs and HICs. Numerous studies found a correlation between the increase in telemedicine/dentistry and the prescription of antibiotics, and the impact of this trend is likely to have a more profound effect on AMR in LMICs.

\section{Compromised antimicrobial stewardship and infection prevention and control measures}

Despite the WHO and NIH guidelines, healthcare employees are unlikely to exercise proper AS when confronted by the need to urgently treat acutely ill patients who are at risk of dying [44].

Recent data from 45 public and private hospitals in Ireland indicate that $76 \%$ of study participants reported that COVID-19 had impacted the effective implementation of AS programs [35]. Additionally, physicians may overprescribe antibiotics as part of defensive medicine, leading to an enhanced selection of resistant bacteria [50]. Such practice protects the prescriber against any malpractice liability. In fact, in a survey of 824 physicians, it was found that almost all practice defensive medicine [49]. A rapid and steep increase in COVID-19-related hospitalizations led to shortages of essential healthcare resources, including ventilators and personal protective equipment (PPE) [60], potentially forcing healthcare workers to share or reuse these resources - a practice that is not uncommon in LMICs [41]. There are also reports of insufficient IPC measures, including gaps in screening for AMR, failure to isolate infected patients, increased patient-to-nurse ratio, and compromised hospital-waste management [2, 24, 43]. Additional factors that may contribute to disruption in IPC measures include a reassignment of IPC staff to support COVID-19 services, reduced availability of diagnostics and other technologies either due to interruptions in the supply chain or overwhelming demand, and shortages of healthcare staff due to travel restrictions. Such disturbances may enhance the further spread of AMR.

To alleviate such negative consequences, the WHO urges the implementation of AS and IPC measures into the pandemic response [26]. Further, due to the clinical uncertainty of SARS-CoV-2 infections, the amount of antibiotics used could have been higher than previous outbreaks, such as the influenza pandemic of 2009 [5]. Collectively, such disruptions across healthcare systems may contribute to the problem that is already estimated to cause 10 million deaths each year by 2050 and push up to 24 million people into extreme poverty by 2030 [58].

\section{The broader use of biocidal agents}

Various biocidal agents and environmental disinfectants have been widely used to potentially reduce the transmission and survival of SARS-CoV-2 on fomites despite the lack of clear scientific evidence of their efficacy in this setting [22]. Many HICs have developed specific guidelines and standard operation protocols for the application of such disinfectants across clinical and home-based healthcare settings [26]. For example, The US Environmental Protection Agency (EPA) evaluates the efficacy of biocidal agents against SARS-CoV-2 and only then provides the EPA Registration Number along with a recommendation for public use [16]. However, the development of such guidelines and regulations and their implementation in LMICs appears to be inadequate. For example, improper use (spraying, fogging streets or marketplaces, sidewalks, tunnel, cabinet, chamber, and full-body spray) of biocides, like cationic agents and triclosan, has been reported [9]. Such disinfecting agents are known to select for antibioticresistant bacteria and can have a broad impact on the environment and human and animal health [13, 14]. The ability of biocides, such as triclosan, to activate multidrug efflux pumps contributes to AMR by selecting bacteria that are resistant to a spectrum of antibiotics [10, 17, 46]. Several studies have linked AMR to the use of common household disinfectants [10, 25] In a recent study, Pidot et al. demonstrated that Enterococcus faecium becomes 
resistant to alcohol-based hand sanitizers [40]. Collectively, there is a justified concern that the excessive use of hand sanitizers and other personal or environmental biocidal agents, including alcohol-based formulas, will contribute to AMR [30].

\section{Interrupted AMR research, innovation, and health programs}

The ongoing pandemic has affected science communication and has delayed scientific research and innovation. Most international collaborative studies and AMR-related activities, including national AMR surveillance programs and clinical trials, have been temporarily suspended, at least during mandatory lockdowns. Such disruptions have severely impacted LMICs, which are especially vulnerable to public health crises [15]. Another obstacle in combatting AMR is redirecting current funding to support COVID-19 research, closure of research institutions, closures of individual laboratories due to local outbreaks, recruitment freezes, and the suspension of ongoing AMR projects [15]. These actions will likely jeopardize the progress of AMR research.

The pandemic has also led to a substantial interruption in global health programs, including routine childhood immunization services, HIV, and TB programs in HIC and LMICs, as recently reported by WHO, UNICEF, and Gavi [26, 56, 57, 61]. Mass vaccination campaigns against cholera, measles, meningitis, polio, tetanus, typhoid, and yellow fever have been temporarily suspended [57]. Although the full extent of the impact of these disruptions on vaccination programs is not yet known, the WHO reports that more than 65 countries are severely affected, and it is estimated that 80 million children under the age of one are at risk for contracting diseases such as diphtheria, measles, and polio [57]. Vaccines play a significant role in reducing the burden of AMR. In LMICs, pneumococcal and rotavirus vaccines prevent an estimated 23.8 million and 13.6 million episodes of antibiotic-treated illness, respectively, each year [55]. Similarly, 74 countries had reported interruptions in the supply of antiretroviral medicines [56]. Such disruptions will severely impact HIVpositive individuals, increase transmission of the disease and the risks of acquiring opportunistic infections, ultimately leading to enhanced demand for antimicrobial therapy.

Each year non-communicable diseases (NCDs) kill approximately 41 million people ( $71 \%$ of all deaths) worldwide, and the majority of premature deaths occur in LMICs [55]. A recent survey of 155 countries conducted by the WHO revealed a significant level of COVID-19related interruption in health services and medicine supply for NCDs such as cancer, cardiovascular diseases, and diabetes mellitus [55]. LMICs are expected to be more significantly affected as self-treatment with over-thecounter medications, including antibiotics, may be expected. Further, such interrupted health services increase immunosuppression and predispose patients afflicted with NCDs to bacterial infections, which could ultimately lead to hospitalization and negatively impact AMR.

\section{Healthcare and household waste}

The dissemination of AMR throughout various domains of One Health, including healthcare, agriculture, and the environment, might be amplified by the ongoing pandemic. Since the start of the COVID-19 outbreak, many countries have experienced a massive increase in healthcare waste [64], compromised waste management, and inadequate handling of pharmaceuticals due to workforce shortages and travel restrictions [24]. Such a lack of waste management can lead to the release of antibiotics and resistant bacteria into the ecosystem via contaminated water, food, or excretion. Therefore, strict implementation of proper waste disposal in healthcare facilities, along with stringent IPC measures and a coordinated, multi-pronged One Health approach to protecting humans, animals, and the environment, is obligatory as part of the strategy to address worsening AMR.

\section{Factors that decreased AMR}

Certain aspects of the pandemic may have potentially slowed down the spread of both pathogenic bacteria and AMR due to disrupted routine care services and the implementation of IPC measures to reduce the risk of healthcare-associated transmission of COVID-19 [19, 43]. Many non-COVID-19 patients did not receive elective care and, therefore, were not exposed to antimicrobials. For example, a recent study of antibiotic usage at VA Pittsburgh observed a reduction of 151.5 antibiotic days of therapy per month that correlated with a significant decrease in hospital admissions driven by the pandemic [12]. Furthermore, the increase in IPC measures, including enforcing face masks, improved hospital hygiene, isolation of patients, the use of appropriate PPEs, visitor screening, and proper respiratory etiquette, contribute to a decrease in healthcare-associated infections and consequently antibiotic use [19]. Similarly, strict lockdown, social distancing, quarantine orders, and extensive emphasis on hand hygiene and sanitation may reduce many endemic community-acquired illnesses such as diarrhea or respiratory infections, which are more prevalent in developing countries. 


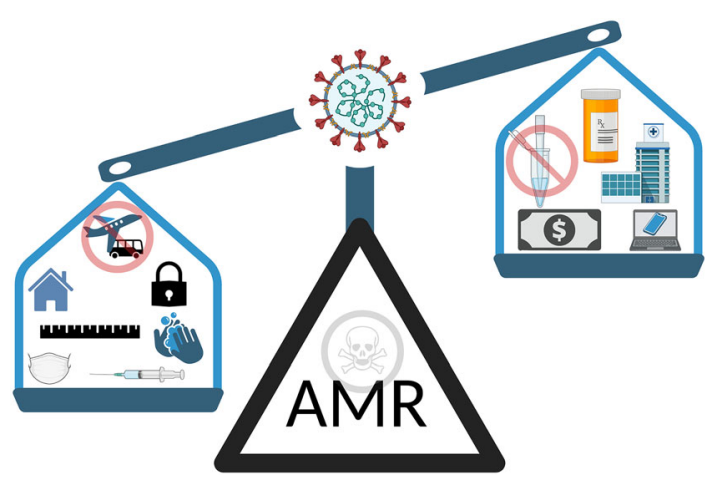

Fig. 1 The impact of COVID-19 on Antimicrobial Resistance. The factors that decrease AMR include the implementation of face masks, social distancing, increased hand hygiene, mandatory lockdowns, stay-at-home orders, vaccination, and travel disruption. The factors contributing to AMR include limited resources, disruption in research, remote medicine/dentistry, overprescription of antibiotics, nosocomial infections, and overwhelmed healthcare. Created using a paid license with BioRender.com

Lockdown of borders, disruption of transportation, and prescription stockpiling have affected drug supply and contributed to reduced access to medication. As such, there may be a reduction in self-medication, including inappropriate antibiotic use, especially in LMICs [43]. Additionally, international travel suspension may substantially reduce the spread of AMR from LMICs to HICs [8].

A coordinated response to the pandemic allowed various professional groups that include physicians, pharmacists, microbiologists, medical scientists, public-health personnel, and policymakers to work together to address the challenge of COVID-19. Therefore, such multi-sectoral efforts may potentially lead to improved IPC and AS programs. Finally, the development and administration of effective vaccines and treatments will stop the pandemic and prevent its further contribution to AMR.

\section{Conclusion}

Antibiotic resistance poses one of the biggest threats to global public health and the economy. While global efforts to curb further development and spread of AMR are being established, the COVID-19 pandemic might have disrupted these efforts and exacerbated the problem; however, the exact impact of the pandemic on AMR is not known yet and can only be speculated at this point. The implementation of face masks, social distancing, increased hand hygiene, mandatory lockdowns, stay-at-home orders, vaccination, travel bans, and disruption in transportation will likely alleviate AMR. In contrast, the lack of funding and limited resources, disruption in research, remote medicine/dentistry, overprescription of antibiotics, nosocomial infections, and overwhelmed healthcare will likely contribute to AMR (Fig. 1). Currently, there is a significant knowledge gap in the nature and burden of coinfections in COVID-19 patients. There are no comprehensive data on the types, frequency, and quantity of antibiotics used and their effect on clinical outcomes in COVID-19 patients and AMR. The use of antibiotics for treatment and prophylaxis varies across countries. Therefore, continuous epidemiological, clinical, and microbiological studies on AMR and nosocomial infections across HIC and LMIC settings are essential to agree on mitigation strategies and treatment guidelines for COVID-19 patients-this is especially important as the international travel restrictions are being lifted. Additionally, proper AS training of the frontline healthcare personnel, antibiotic awareness education among the general public, and AMR legislation implementation are critical to reducing AMR, especially in LMICs. Other solutions include modifying patient satisfaction surveys as a metric to evaluate medical services and the performance of medical providers; such a strategy would mitigate the overprescription of antibiotics and the practice of defensive medicine. Furthermore, combating AMR also depends on how individual countries overcome disrupted public health measures, economies, and governance structures during the pandemic, particularly in LMICs.

Even though effective vaccines have been developed and vaccination is ongoing, the future of the COVID-19 pandemic is still uncertain given the emergence of new variants. If no stringent actions are taken to halt the potential adverse impact of COVID-19 on AMR, an increase of antibiotic resistance among clinically relevant bacterial pathogens may lead to disastrous long-term consequences. One of the crucial solutions is to eliminate SARS-CoV-2 as the potential contributor to AMR by calling government officials to strictly enforce face masks, personal hygiene, and social distancing until the vaccination has been reached worldwide.

Although the effect of the pandemic is global, the adverse consequences are likely to be worse in LMICs that are already grappling with a higher burden of AMR and endemic infectious diseases. Therefore, aggressive AS and IPC interventions in hospitals, clinics, and the community, are essential to secure a sustainable future. Accordingly, concentrated global efforts and leadership with a higher level of public involvement and international cooperation are urgently needed to curb the adverse impact of the pandemic on AMR.

Author contributions All authors (SHS, DMC, KPA \& HH) equally contributed to the concept of the manuscript and identified relevant data. SHS initiated, designed and wrote the first draft of the 
manuscript along with DMC, which was critically revised and approved by all authors for submission.

Funding This work was not supported by funding.

Data availability Data sharing is not applicable to this article as no new data were created or analyzed in this study.

\section{Declarations}

Conflict of interest $\mathrm{HH}$ has recently been in receipt of research funding from Astellas and Pfizer has received a consultancy fee from Pfizer in the last three years. All other authors have no conflicts of interest to declare.

Ethical approval The authors confirm that the ethical policies of the journal, as noted on the journal's author guidelines page, have been adhered to.

\section{References}

1. Ajibola O, Omisakin OA, Eze AA, et al. Self-Medication with Antibiotics, Attitude and Knowledge of Antibiotic Resistance among Community Residents and Undergraduate Students in Northwest Nigeria. Diseases. 2018;6(2):32. https://doi.org/10. 3390/diseases6020032.

2. Antimicrobial resistance in the age of COVID-19. Nat Microbiol. 2020;5:779. https://doi.org/10.1038/s41564-020-0739-4.

3. Armitage R, Nellums LB. Antibiotic prescribing in general practice during COVID-19. Lancet Infect Dis. 2020. https://doi. org/10.1016/S1473-3099(20)30917-8.

4. Barach P, Fisher SD, Adams MJ, et al. Disruption of healthcare: Will the COVID pandemic worsen non-COVID outcomes and disease outbreaks? Prog Pediatr Cardiol. 2020. https://doi.org/10. 1016/j.ppedcard.2020.101254.

5. Bengoechea JA, Bamford CGG. SARS-CoV-2, bacterial co-infections, and AMR: the deadly trio in COVID-19? EMBO Mol Med. 2020;12(7):e12560. https://doi.org/10.15252/emmm. 202012560.

6. Bengoechea JA, Sa PJ. Klebsiella pneumoniae infection biology: living to counteract host defences. FEMS Microbiol Rev. 2019;43(2):123-44. https://doi.org/10.1093/femsre/fuy043.

7. Beovic B, Dousak M, Ferreira-Coimbra J, et al. Antibiotic use in patients with COVID-19: A 'snapshot' infectious diseases international research initiative (ID-IRI) survey. J Antimicrob Chemother. 2020;75:3386. https://doi.org/10.1093/jac/dkaa326.

8. Berndtson AE. Increasing globalization and the movement of antimicrobial resistance between countries. Surg Infect (Larchmt). 2020;21:579. https://doi.org/10.1089/sur.2020.145.

9. Biswal M, Kanaujia R, Angrup A, et al. Disinfection tunnels: potentially counterproductive in the context of a prolonged pandemic of COVID-19. Public Health. 2020;183:48. https://doi.org/ 10.1016/j.puhe.2020.04.045.

10. Blanco P, Hernando-Amado S, Reales-Calderon J, et al. Bacterial multidrug efflux pumps: much more than antibiotic resistance determinants. Microorganisms. 2016;4:14. https://doi.org/10. 3390/microorganisms4010014.

11. Board of Governors - Indian Medical Council. In supersession of the Medical Council of India Telemedicine Practice Guidelines. Indian Med Counc. 2020. https://www.mohfw.gov.in/pdf/Tele medicine.pdf.

12. Buehrle DJ, Decker BK, Wagener MM, et al. Antibiotic Consumption and Stewardship at a Hospital outside of an Early
Coronavirus Disease 2019 Epicenter. Antimicrob Agents Chemother. 2020;64(11):e01011-20. https://doi.org/10.1128/AAC. 01011-20.

13. Capita R, Vicente-Velasco M, Rodríguez-Melcón C, et al. Effect of low doses of biocides on the antimicrobial resistance and the biofilms of Cronobacter sakazakii and Yersinia enterocolitica. Sci Rep. 2019;9:15905. https://doi.org/10.1038/s41598-019-51907-1.

14. Carey DE, McNamara PJ. The impact of triclosan on the spread of antibiotic resistance in the environment. Front Microbiol. 2015;5:780. https://doi.org/10.3389/fmicb.2014.00780.

15. Cascella M, Rajnik M, Aleem A, et al. Features, evaluation, and treatment of coronavirus (COVID-19). In: StatPearls. Treasure Island (FL): StatPearls Publishing; 2021. Available from: https:// www.ncbi.nlm.nih.gov/books/NBK554776/.

16. CDC. Guidance for Cleaning and Disinfecting. US Centers Dis Control Prev [Internet]. 2020; 1-9. https://www.cdc.gov/cor onavirus/2019-ncov/community/pdf/Reopening_America_Gui dance.pdf.

17. Chuanchuen R, Beinlich K, Hoang TT, et al. Cross-resistance between triclosan and antibiotics in Pseudomonas aeruginosa is mediated by multidrug efflux pumps: exposure of a susceptible mutant strain to triclosan selects $\mathrm{nfxB}$ mutants overexpressing MexCD-OprJ. Antimicrob Agents Chemother. 2001;45 (2):428-32. https://doi.org/10.1128/AAC.45.2.428-432.2001.

18. Clancy CJ, Nguyen MH. Coronavirus disease 2019, superinfections, and antimicrobial development: What can we expect? Clin Infect Dis. 2020;71:2736. https://doi.org/10.1093/cid/ciaa524.

19. Collignon P, Beggs JJCON. COVID-19 will not result in increased antimicrobial resistance prevalence. JAC Antimicrob Resist. 2020;2(3):dlaa051. https://doi.org/10.1093/jacamr/ dlaa051.

20. Could new covid variants undermine vaccines? Labs scramble to find out. The world this week. News in focus. Nature. 2021; 589. https://media.nature.com/original/magazine-assets/d41586-02100031-0/d41586-021-00031-0.pdf.

21. Cox MJ, Loman N, Bogaert D, et al. Co-infections: potentially lethal and unexplored in COVID-19. Lancet Microbe. 2020;1:e11. https://doi.org/10.1016/S2666-5247(20)30009-4.

22. Dev Kumar G, Mishra A, Dunn L, et al. Biocides and Novel Antimicrobial Agents for the Mitigation of Coronaviruses. Front Microbiol. 2020;11:1351. https://doi.org/10.3389/fmicb.2020. 01351.

23. Do NTT, Vu HTL, et al. Community-based antibiotic access and use in six low-income and middle-income countries: a mixedmethod approach. Lancet Glob Health. 2021;1:11-225. https:// doi.org/10.1016/s2214-109x(21)00024-3.

24. European Commission. Waste management in the context of the coronavirus crisis [Internet]. 2020; s. 5. https://www.ecdc.europa. eu/en/publications-data/disinfection-environments-covid-19.

25. Fahimipour AK, Ben Mamaar S, McFarland AG, et al. Antimicrobial chemicals associate with microbial function and antibiotic resistance indoors. mSystems. 2018;3:e00200-18. https://doi.org/ $10.1128 / \mathrm{mSystems} .00200-18$.

26. Getahun H, Smith I, Trivedi K, et al. Tackling antimicrobial resistance in the COVID-19 pandemic. Bull. World Health Organ. 2020. https://www.who.int/bulletin/volumes/98/7/20268573/en/.

27. Han SM, Greenfield G, Majeed A, et al. Impact of remote consultations on antibiotic prescribing in primary health care: systematic review. J Med Internet Res. 2020;22(11):e23482 https://doi.org/ 10.2196/23482. (PMID:33031045; PMCID:PMC7655728).

28. Huang C, Wang Y, Li X, et al. Clinical features of patients infected with 2019 novel coronavirus in Wuhan. China. Lancet. 2020;395:497. https://doi.org/10.1016/S0140-6736(20)30183-5.

29. International Severe Acute Respiratory and Emerging Infection Consortium. COVID-19 Report. 2020; Získáno z: https://media. 
tghn.org/medialibrary/2020/04/ISARIC_Data_Platform_COVID19_Report_8APR20.pdf.

30. Kampf G. Biocidal agents used for disinfection can enhance antibiotic resistance in gram-negative species. Antibiotics. 2018;7:110. https://doi.org/10.3390/antibiotics7040110.

31. Karagiannidis C, Mostert C, Hentschker C, et al. Case characteristics, resource use, and outcomes of 10,021 patients with COVID-19 admitted to 920 German hospitals: an observational study. Lancet Respir Med. 2020;8:853. https://doi.org/10.1016/ S2213-2600(20)30316-7.

32. Langford BJ, So M, Raybardhan S, et al. Bacterial co-infection and secondary infection in patients with COVID-19: a living rapid review and meta-analysis. Clin Microbiol Infect. 2020;12:1622-9. https://doi.org/10.1016/j.cmi.2020.07.016.

33. Liberati A, D'Amico R, Pifferi S, et al. Antibiotic prophylaxis to reduce respiratory tract infections and mortality in adults receiving intensive care. Cochrane Database Syst Rev. 2009;2009(4):CD000022. https://doi.org/10.1002/14651858. CD000022.

34. MacIntyre CR, Chughtai AA, Barnes $M$, et al. The role of pneumonia and secondary bacterial infection in fatal and serious outcomes of pandemic influenza a(H1N1)pdm09. BMC Infect Dis. 2018;18(1):637. https://doi.org/10.1186/s12879-018-3548-0.

35. Martin E, Philbin M, Hughes G, et al. Antimicrobial stewardship challenges and innovative initiatives in the acute hospital setting during the COVID-19 pandemic. J Antimicrob Chemother. 2020;76:272. https://doi.org/10.1093/jac/dkaa400.

36. Martinez KA, Rood M, Jhangiani N, et al. Association between antibiotic prescribing for respiratory tract infections and patient satisfaction in direct-to-consumer telemedicine. JAMA Intern Med. 2018;178(11):1558-60. https://doi.org/10.1001/jamain ternmed.2018.4318.

37. Molento MB. COVID-19 and the rush for self-medication and self-dosing with ivermectin: a word of caution. One Health. 2020;10:100148. https://doi.org/10.1016/j.onehlt.2020.100148.

38. Morris DE, Cleary DW, Clarke SC. Secondary Bacterial Infections Associated with Influenza Pandemics. Front Microbiol. 2017;8:1041. https://doi.org/10.3389/fmicb.2017.01041.

39. NIH, COVID-19 treatment guidelines. Clinical spectrum of SARS-CoV-2 infection. Last Updated: December 17, 2020. https://www.covid19treatmentguidelines.nih.gov/overview/clin ical-spectrum/.

40. Pidot SJ, Gao W, Buultjens AH, Monk IR, et al. Increasing tolerance of hospital enterococcus faecium to handwash alcohols. Sci Transl Med. 2018;10(452):eaar6115. https://doi.org/10.1126/ scitranslmed.aar6115.

41. Popp W, Rasslan O, Unahalekhaka A, et al. What is the use? An international look at reuse of single-use medical devices. Int $\mathbf{J}$ Hyg Environ Health. 2010;213(4):302-7. https://doi.org/10.1016/ j.ijheh.2010.04.003.

42. Rawson TM, Moore LSP, Zhu N, et al. Bacterial and fungal coinfection in individuals with coronavirus: a rapid review to support COVID-19 antimicrobial prescribing. Clin Infect Dis. 2020;71(9):2459-68. https://doi.org/10.1093/cid/ciaa530.

43. Rawson TM, Moore LSP, Castro-Sanchez E, et al. COVID-19 and the potential long-term impact on antimicrobial resistance. J Antimicrob Chemother. 2020;75:1681. https://doi.org/10.1093/ jac/dkaa194.

44. Reardon S. Antibiotic treatment for COVID-19 complications could fuel resistant bacteria. Science. Accessed 16 Apr 2020. https://www.sciencemag.org/news/2020/04/antibiotic-treatmentcovid-19-complications-could-fuel-resistant-bacteria.

45. Rodrigues CF. Self-medication with antibiotics in Maputo, Mozambique: practices, rationales and relationships. Palgrave Commun. 2020;6:6. https://doi.org/10.1057/s41599-019-0385-8.
46. Russell AD. Introduction of biocides into clinical practice and the impact on antibiotic-resistant bacteria. J Appl Microbiol. 2002;92:121S-35S. (PMID: 12000621).

47. Shah S, Wordley V, Thompson W. How did COVID-19 impact on dental antibiotic prescribing across England? $\mathrm{Br}$ Dent $\mathrm{J}$. 2020;229:601-4. https://doi.org/10.1038/s41415-020-2336-6.

48. Shaver AL, Jacobs DM, LaMonte MJ, et al. Antibiotic prescribing for acute respiratory tract infections in the United States outpatient setting. BMC Fam Pract. 2019;20(1):91. https://doi. org/10.1186/s12875-019-0980-1.

49. Studdert DM, Mello MM, Sage WM, et al. Defensive medicine among high-risk specialist physicians in a volatile malpractice environment. JAMA. 2005;293(21):2609-17. https://doi.org/10. 1001/jama.293.21.2609.

50. Tebano G, Dyar OJ, Beovic B, et al. Defensive medicine among antibiotic stewards: the international ESCMID AntibioLegalMap survey. J Antimicrob Chemother. 2018;73:1989. https://doi.org/ 10.1093/jac/dky098.

51. Tian S, Xiong Y, Liu H, et al. Pathological study of the 2019 novel coronavirus disease (COVID-19) through postmortem core biopsies. Mod Pathol. 2020;33:1007-14. https://doi.org/10.1038/ s41379-020-0536-x.

52. Torres NF, Chibi B, Middleton LE, et al. Evidence of factors influencing self-medication with antibiotics in low and middle income countries: a systematic scoping review. Public Health. 2019;168:92-101. https://doi.org/10.1016/j.puhe.2018.11.018.

53. Vaughn VM, Gandhi T, Petty LA, et al. Empiric Antibacterial Therapy and Community-onset Bacterial Co-infection in Patients Hospitalized with COVID-19: A Multi-Hospital Cohort Study. Clin Infect Dis. 2020;21:ciaa1239. https://doi.org/10.1093/cid/ ciaa1239.

54. Versteeg GA, Bredenbeek PJ, van den Worm SHE, et al. Group 2 coronaviruses prevent immediate early interferon induction by protection of viral RNA from host cell recognition. Virology. 2007;361:18. https://doi.org/10.1016/j.virol.2007.01.020.

55. WHO. COVID-19 significantly impacts health services for noncommunicable diseases [Internet]. 2020. s. 1-3. Získáno z: https://www.who.int/news-room/detail/01-06-2020-covid-19-sig nificantly-impacts-health-services-for-noncommunicablediseases.

56. WHO. Access to HIV medicines severely impacted by COVID19 as AIDS response stalls [Internet]. World Heal. Organ. 2020. Získáno z: https://www.who.int/news-room/detail/06-07-2020who-access-to-hiv-medicines-severely-impacted-by-covid-19-asaids-response-stalls.

57. WHO. At least 80 million children under one at risk of diseases such as diphtheria, measles and polio as COVID-19 disrupts routine vaccination efforts, warn Gavi, WHO and UNICEF [Internet]. World Heal. Organ. 2020. s. 22-5. Získáno z: https:// www.who.int/news-room/detail/22-05-2020-at-least-80-millionchildren-under-one-at-risk-of-diseases-such-as-diphtheriameasles-and-polio-as-covid-19-disrupts-routine-vaccinationefforts-warn-gavi-who-and-unicef.

58. WHO. New report calls for urgent action to avert antimicrobial resistance crisis. 29 April 2019, Joint News Release [Internet]. https://www.who.int/news/item/29-04-2019-new-report-calls-forurgent-action-to-avert-antimicrobial-resistance-crisis.

59. World Economic Forum. The economic, geopolitical and health impacts of COVID-19 | World Economic Forum [Internet]. 2020. Získáno z: https://www.weforum.org/agenda/2020/03/the-eco nomic-geopolitical-and-health-consequences-of-covid-19/.

60. World Health Organization. Shortage of personal protective equipment endangering health workers worldwide [Internet]. 3 March 2020 News release. https://www.who.int/news/item/0303-2020-shortage-of-personal-protective-equipment-endanger ing-health-workers-worldwide. 
61. World Health Organization. Tuberculosis and COVID-19: Considerations for tuberculosis care. World Heal Organ [Internet]. 2020;1-11. Získáno z: https://www.who.int/docs/default-source/ documents/tuberculosis/infonote-tb-covid-19.pdf.

62. Worldometer. Coronavirus Update (Live): Cases and Deaths from COVID-19 Virus Pandemic [Internet]. Worldometers. 2020. s. 1. Získáno z: https://www.worldometers.info/coronavirus/?

63. $\mathrm{Xu} X W, \mathrm{Wu} X X$, Jiang $\mathrm{XG}$, et al. Clinical findings in a group of patients infected with the 2019 novel coronavirus (SARS-Cov-2) outside of Wuhan, China: retrospective case series. BMJ 2020;368. https://doi.org/10.1136/bmj.m792.

64. You S, Sonne C, Ok YS. Covid-19's unsustainable waste management. Science. 2020;368:1438. https://doi.org/10.1126/sci ence.abc7778.

65. Zhang A, Hobman EV, De Barro P, et al. Self-medication with antibiotics for protection against COVID-19: the role of psychological distress, knowledge of, and experiences with antibiotics. Antibiotics (Basel). 2021;10(3):232. https://doi.org/ 10.3390/antibiotics10030232.

66. Zhou F, Yu T, Du R, et al. Clinical course and risk factors for mortality of adult inpatients with COVID-19 in Wuhan, China: a retrospective cohort study. Lancet. 2020;395:1054. https://doi. org/10.1016/S0140-6736(20)30566-3.

67. Zhu N, Aylin P, Rawson T, et al. Investigating the impact of COVID-19 on primary care antibiotic prescribing in North West London across two epidemic waves. Clin Microbiol Infect. 2021;27(5):762-8. https://doi.org/10.1016/j.cmi.2021.02.007.

68. Zhu X, Ge Y, Wu T, et al. Co-infection with respiratory pathogens among COVID-2019 cases. Virus Res. 2020;285:198005. https://doi.org/10.1016/j.virusres.2020.198005.

Publisher's Note Springer Nature remains neutral with regard to jurisdictional claims in published maps and institutional affiliations. 